\title{
Spatial conservation prioritization inclusive of wilderness quality: A case study of Australia's biodiversity
}

\author{
Carissa J. Klein ${ }^{\mathrm{a}, *}$, Kerrie A. Wilson ${ }^{\mathrm{a}}$, Matthew Watts ${ }^{\mathrm{a}}$, Janet Stein ${ }^{\mathrm{b}}$, Josie Carwardine ${ }^{\mathrm{a}}$, \\ Brendan Mackey ${ }^{\mathrm{b}}$, Hugh P. Possingham ${ }^{\mathrm{a}}$ \\ ${ }^{a}$ The University of Queensland, The Ecology Centre, Applied Environmental Decision and Analysis, St. Lucia, Queensland 4072, Australia \\ ${ }^{\mathrm{b}}$ Australian National University, The Fenner School of Environment and Society, Canberra, ACT 0200, Australia
}

\section{A R T I C L E I N F O}

\section{Article history:}

Received 12 September 2008

Received in revised form 12 January 2009

Accepted 17 January 2009

Available online 17 March 2009

\section{Keywords:}

Adequacy

Intact

Marxan

Protected area

Trade-off

Watershed

\begin{abstract}
A B S T R A C T
There is considerable discussion about the relative importance of conserving high quality wilderness areas (i.e. large and intact landscapes) versus conserving areas with high biodiversity values. Places that are needed to achieve one aspect of biodiversity conservation are not necessarily optimal for another which can lead to conflict in assigning conservation priorities. However, both are important for biodiversity conservation, and carry social, economic, and ecological values. Investment in both (a) representation of elements of biodiversity (e.g. species, habitats) and (b) wilderness conservation is not only complementary but important for the long-term persistence of biodiversity. We develop two approaches to identify areas important for the conservation of biodiversity in terms of both wilderness quality and biodiversity representation, using Australia as a case study. We defined intact areas as sub-catchments with at least $70 \%$ or more vegetation that has not been subjected to extensive habitat loss and fragmentation as the result of land clearing. The first approach aims to achieve biodiversity representation goals in areas with intact native vegetation. The results of this approach would be extremely expensive to implement as they require a large portion of land. The second approach aims to achieve biodiversity representation goals anywhere across the landscape while placing a strong emphasis on identifying spatially compact intact areas. The results of this approach show the trade-offs between the economic costs of conservation and the size of conservation areas containing intact native vegetation. This manuscript provides a novel framework for identifying cost-effective biodiversity conservation priorities inclusive of wilderness quality.
\end{abstract}

(c) 2009 Elsevier Ltd. All rights reserved.

\section{Introduction}

Biodiversity conservation aims to protect the variability among living things, including the diversity within species, between species, and of ecosystems (United Nations, 1992). The principles of protected area network establishment often include goals to comprehensively represent elements of biodiversity. However, protected areas that comprehensively protect representative elements of biodiversity may not be adequate for the long-term persistence of biodiversity (Possingham et al., 2006; Soulé and Sanjayan, 1998). For example, if size and condition are not considered in the identification of priority areas for biodiversity conservation, they may not be adequate to facilitate large-scale and long-term ecological processes (e.g. migrations and dispersal) and change (e.g. climate variability and fluxes) (Soule et al.,

\footnotetext{
* Corresponding author. Tel.: +61 73365 3539; fax: +61 733651655

E-mail addresses: c.klein@uq.edu.au (C.J. Klein), k.wilson2@uq.edu.au (K.A. Wilson),m.watts@uq.edu.au (M. Watts), janet.stein@anu.edu.au (J. Stein), j.carwardine@uq.edu.au (J. Carwardine), brendan.mackey@anu.edu.au (B. Mackey).
}

2004). Wilderness quality is one useful spatial surrogate for the long-term persistence of biodiversity and can be used to identify spatial conservation priorities. High quality wilderness areas, or large and intact areas, play an important role in sustaining ecological and evolutionary processes that maintain and generate biodiversity (Frankel and Soule, 1981; Geider et al., 2001; Solan et al. 2004; Thompson, 2005).

The wilderness quality of land can be measured as a continuum using various indicators but most commonly surrogates of human land use and infrastructure (Lesslie, 1991). As Indigenous huntergatherer societies occupied all continents except Antarctica for the last 14-50,000 years (Mulvaney and Kamminga, 1999), it is difficult to determine their ecological footprint. Therefore, the baseline wilderness quality is commonly taken as the land condition prior to European settlement as this coincides with the advent of modern industrialized land use activities including broad-scale land clearing and the large-scale impoundment and diversion of water (Fahrig, 1997; Glanznig, 1995). It follows that land with a relatively high wilderness quality has its native vegetation cover largely intact. 
There is considerable discussion about the relative importance of conserving areas with high wilderness quality versus conserving areas with high biodiversity values (Booth and Traill, 2008; Mittermeier et al., 1998; Redford et al., 2003; Sarkar, 1999). The places that are needed to achieve one aspect of biodiversity conservation are not necessarily optimal for another which can lead to conflict in assigning priorities for conservation investment (Mittermeier et al., 2003).

In a global study of important areas for wilderness conservation, Mittermeier et al. (2003) found that wilderness areas, covering $44 \%$ of the Earth's land area, are generally not species rich and concluded that the conservation of wilderness per se does not ensure the protection of biodiversity. Likewise, since areas of high biodiversity value typically coincide with areas of high human population density, the conservation of biodiversity may not ensure the protection of wilderness (Balmford et al., 2001). There are two reasons why the geographic distribution of wilderness areas may not coincide with places important for threatened species conservation or to meet biodiversity representation goals. First, where the major cause of the species or ecosystem's threatened status has been habitat loss and fragmentation then, by definition, the remnant populations will be located in areas with a low wilderness quality. Second, the definition of wilderness quality hinges primarily on the condition of the vegetation (Thackway et al., 2007) and includes no reference to useful surrogates of biodiversity value, such as endemism and level of extinction risk. It follows that in terms of spatial conservation prioritization, wilderness areas may or may not be a priority for meeting the goal of comprehensive biodiversity representation. Given limited resources available for conservation, should we invest in protecting areas of high wilderness quality or invest in protecting areas with high biodiversity values?

This question is an unnecessarily stark dichotomy, since both are important for the conservation of biodiversity, and carry social, economic, and ecological values (Callicott and Nelson, 1998; United Nations, 1992; World Conservation Union, 1994). High quality wilderness areas sustain critical ecological processes (e.g. water filtration, carbon sequestration, and nitrogen fixation) that constitute Earth's life support systems (e.g. provision of clean water and air, climatic stability) (Grumbine, 1990; Mittermeier et al., 2003). They also support local economies by providing renewable resources and by attracting tourism, and are important for cultural and religious values (Cronon, 1995). Biodiversity plays a critical role in sustaining ecological processes (Gilmore et al., 2007; Pressey et al., 2003), makes important economic contributions to agricultural and medicinal industries, and is significant for certain cultural traditions (United Nations, 1992). If no steps are taken to protect wilderness areas, these areas may eventually be subject to habitat loss and fragmentation, and accompanying loss of biodiversity. Therefore investment in both (a) representation of elements of biodiversity (e.g. species, habitats) and (b) wilderness conservation is not only complementary but important for the long-term persistence of biodiversity.

As a compromise, Mittermeier et al. (2003) suggests that we focus our conservation investments on species rich wilderness areas, such as those in parts of Amazonian Brazil, the Congo Basin, and Northern Australia. Although these areas may adequately address wilderness conservation objectives, these areas alone will not meet the biodiversity conservation objective of comprehensively representing biodiversity in a network of conservation areas. Identifying areas important for the conservation of biodiversity on the basis of species richness does not ensure that all species are represented as it fails to account for the principle of complementarity - the contribution of the total set of selected areas (i.e. currently protected areas or other areas included in the conservation plan) towards representing biodiversity (Williams et al., 1996).
We develop two alternative approaches to identify areas important for the conservation of biodiversity in terms of both wilderness quality and biodiversity representation. In the first approach we achieve biodiversity representation goals in areas with intact native vegetation. In the second approach we achieve biodiversity representation goals anywhere across the landscape while placing an emphasis on identifying spatially compact intact areas. To achieve biodiversity representation objectives, we identify areas that comprehensively represent a wide spectrum of biodiversity features using the principle of complementarity. Finally, since there are limited funds available for conservation, we achieve these objectives for a minimum cost, where the cost is determined by the conservation action under consideration, which in this case is the purchase of land for protection (Carwardine et al., 2008; Naidoo et al., 2006). Other conservation actions (e.g. stewardship agreements with private land holders) could be assessed using our prioritization approaches.

We test our approaches in Australia (Fig. 1) - a country considered to be globally significant for both biodiversity and the existence of areas of high wilderness quality (Booth and Traill, 2008; Mittermeier et al., 2003; Mittermeier et al., 2004). In March 2008, the Australian government announced a commitment of $\$ 180$ million dollars to expand the National Reserve System (Department of the Environment, 2008). This money will, in part, be dedicated to the acquisition of additional land for protection and is a primary reason we have focused on identifying land acquisition priorities in this paper. Systematic conservation planning in Australia has given priority to comprehensively representing habitats and species, without sufficient regard to the issue of adequacy and the protection of large and intact areas (Commonwealth of Australia, 2005). However, there is increasing recognition of the importance to biodiversity conservation of protecting high quality wilderness areas in Australia (Woinarski et al., 2007) with several international and national agencies establishing multi-million dollar initiatives with this mandate (Booth and Traill, 2008; Kenney, 2007).

\section{Methods}

We used sub-catchments (aka watersheds) as the planning unit $(n=62,630)$ for the selection of priority areas in our analysis as they are more amenable at capturing ecological processes than the more commonly used square or hexagon planning units (Klein et al., 2009). The sub-catchments are an average size of $50 \mathrm{~km}^{2}$ and $800 \mathrm{~km}^{2}$ in the intensive and extensive land use zones, respectively.

\subsection{Defining intact areas}

We define intact as those areas where the vegetation cover has not been severely modified since European arrival. We use a classification called VAST (Vegetation Assets, States and Transitions), which categorizes land cover into seven states according to the degree of post-European settlement anthropogenic modification as the result of land use activities including pastoralism, intensive agriculture and timber harvesting (Thackway and Lesslie, 2006; Thackway et al., 2007). The VAST framework has been applied to the Australian continent using available land cover and land use data, producing a geographic data layer in raster format at a $1 \mathrm{~km}$ grid cell resolution. Of the seven classes, we used the two classes ('Bare and Residual') containing the least modified vegetation to define 'intactness' and identified sub-catchments with at least $50 \%, 70 \%$, and $90 \%$ of these VAST classes to illustrate the spatial variation arising from using different thresholds of intactness. 

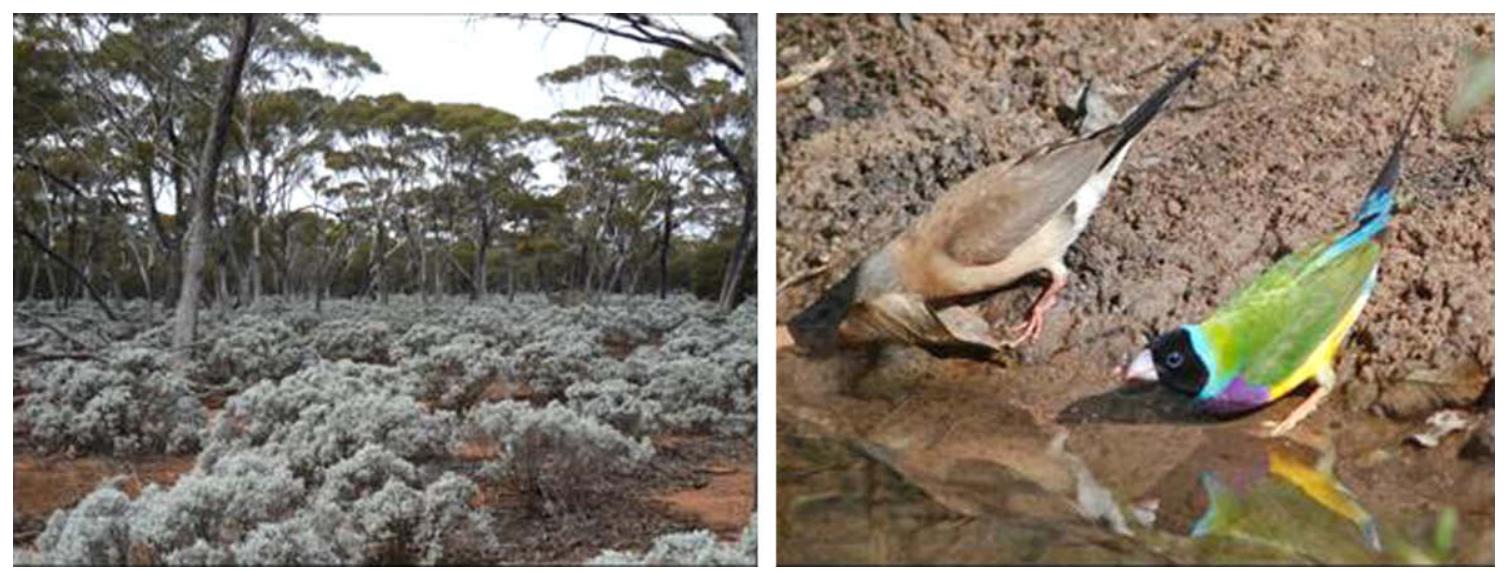

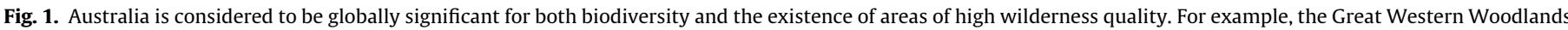

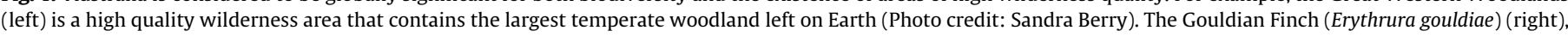
an endangered species, is endemic to Northern Australia and is just one example of the continent's unique biota (Photo credit: Keith Basseley).

\subsection{Representation of biodiversity}

Using the best national scale, publicly-available biological data available for Australia (identified in Carwardine et al., 2008), we represented elements of biodiversity using major vegetation types, environmental domains, bird and threatened species distributions. We identified vegetation types by intersecting 62 native vegetation sub-groups (The National Vegetation Information System, 2001) with the 85 bioregions (Australian Government, 2004). Environmental domains were represented by a continental environmental classification calculated by Mackey et al. (2008) based on a set of key climatic, topographic, and substrate conditions that characterise the landscape. Bird species distributions were modelled from bird location data (Birds Australia, 2005) using alpha hulls (Burgman and Fox, 2003). We did not include distribution data for introduced, vagrant, wintering, or sea birds. We identified data for threatened flora and fauna (excluding birds) that are listed in the EPBC Act (Commonwealth of Australia, 1999). In total, we considered 1763 unique vegetation types (vegetation subgroup/bioregion combinations), 151 environmental domains, 563 bird species, and 1222 species of national significance, referred to herein as biodiversity features. We determined the current extent of each biodiversity feature in each sub-catchment and the extent prior to 1770 , which was assumed to represent pre-clearing estimates. Since our prioritisation analyses concerned only areas of native vegetation, we did not consider biodiversity features that occurred in areas that have been cleared or contain extensively modified vegetation, thereby assuming that areas of non-native vegetation do not contribute to our conservation targets. A more detailed description of the data and processing methods are described in Carwardine et al. (2008).

\subsection{Cost}

We aim to identify spatial priorities for conservation investment that minimize the cost of acquiring land subject to the constraint that biodiversity and wilderness conservation objectives are achieved. We used a cost measure that represents the cost of acquiring all areas of native vegetation within each sub-catchment, generated from average unimproved land values in each local government area (Carwardine et al., 2008). By using the acquisition cost of land, we assume the conservation action under consideration is land acquisition.

\subsection{Site prioritization approach}

We identify spatial priorities that consider biodiversity representation and wilderness conservation objectives using the Marxan conservation planning software (Ball and Possingham, 2000). Marxan uses a simulated annealing algorithm to configure areas that minimize the sum of the planning unit and boundary costs while ensuring that biodiversity targets are met (Possingham et al. 2000). We aimed to include $30 \%$ of each biodiversity feature while minimizing the economic cost of the system of selected areas. We set conservation targets for each feature at 30\% of their pre-clearing (year 1770) extent to be consistent with international recommendations (IUCN, 2003) and to ensure that biodiversity features are represented in proportion to their natural extent. Sub-catchments that are currently greater than $50 \%$ protected (IUCN status I-IV) were not available for selection but the biodiversity contained within them contributed towards the biodiversity targets.

\subsubsection{Baseline scenario (no consideration of wilderness quality)}

We identified sets of sub-catchments for biodiversity conservation that represent $30 \%$ of each biodiversity feature for a minimum economic cost, a common approach used to identify spatial priorities for conservation assessment (Cowling et al., 2003; Margules and Pressey, 2000; Possingham et al., 2006). We compare the results of this approach to the target and cluster approaches (described below) that consider an additional objective of identifying large intact areas.

\subsubsection{Target scenario (representation targets are preferentially met in intact planning units) \\ We identified sets of sub-catchments for biodiversity conserva- tion that preferentially represented $30 \%$ of each biodiversity fea- ture in intact sub-catchments, for a minimum economic cost. If the target, or a portion of the target, could not be met in an intact sub-catchment, then it was satisfied in a non-intact sub- catchment.}

\subsubsection{Clustering scenario (representation targets are met with a strong} emphasis on areas that are spatially compact and intact)

We identified sets of sub-catchments for biodiversity conservation that represent $30 \%$ of each biodiversity feature for a minimum economic cost while placing emphasis on selecting groups (or clusters) of adjacent intact sub-catchments. To achieve this we placed a boundary cost (equal to the boundary length) between intact subcatchments and used Marxan to identify sets of sub-catchments that minimize the sum of the planning unit and boundary costs while ensuring biodiversity targets are achieved. The relative importance of minimizing the boundary of the network relative to the total planning unit cost can be controlled with a parameter called the boundary length modifier. As the modifier was in- 
creased, greater emphasis was placed on minimizing the boundary length relative to minimizing the cost; resulting in the identification of groups of adjacent planning units that meet our objectives. We varied the boundary length modifier to explore the trade-off between identifying large intact areas and minimizing the overall cost of the reserve system.

Using the simulated annealing and iterative improvement features of Marxan, we generated 500 different solutions that satisfy the objectives of each scenario. In addition to the best solution (that which meets targets for a minimum cost), we show the selection frequency (number of times an individual sub-catchment is selected out of 500 solutions) to highlight how often each subcatchment contributes towards achieving our objective. We consider priority areas to be those selected in every solution (selection frequency $=100 \%$ ).

\section{Results}

\subsection{Intact areas}

We identified sub-catchments with at least $50 \%, 70 \%$, and $90 \%$ of unmodified vegetation (Fig. 2). In this paper, we considered subcatchments containing $70 \%$ or greater of unmodified vegetation to be intact in order to be consistent with previous studies (Hannah et al., 1995; Mittermeier et al., 2003). Intact sub-catchments comprised $18 \%$ of the sub-catchments and $36 \%$ of Australia. Unreserved intact sub-catchments cover an area of 2,450,741 $\mathrm{km}^{2}$.

\subsection{Site prioritization}

We compare the total and intact area selected by the baseline, target, and cluster approaches (Fig. 3). In the target approach, $100 \%$ of the intact area was required to achieve the biodiversity representation targets (Fig. 3). Therefore, when we aim to preferentially achieve the biodiversity representation targets $(30 \%$ of each feature, when possible) in intact sub-catchments, a majority of the continent is prioritized. The cluster approach produces solutions that do not require the entire extent of intact area to achieve both biodiversity representation and wilderness objectives (Fig. 3). In the cluster approach, we varied the boundary length modifier to identify solutions with low, moderate, and high degrees of clustering of intact sub-catchments (Fig. 4). As a result of increasing the boundary length modifier from 0 (same as baseline biodiversity approach), we found: (1) an increase in the overall area of intact subcatchments selected (Fig. 3); and (2) an increase in the spatial compactness, or clustering, of intact sub-catchments (Fig. 5).

In comparison to the baseline scenario, both the target and cluster approaches select more intact area (Fig. 3). As a result, more overall area is required as certain sub-catchments outside the intact area are needed to achieve the biodiversity targets as they contain biodiversity features that do not exist in other parts of the landscape (e.g. southwestern Australia) (Fig. 6). Although entire sub-catchments are highlighted as a priority, only the native vegetation within these sub-catchments would be considered for acquisition.

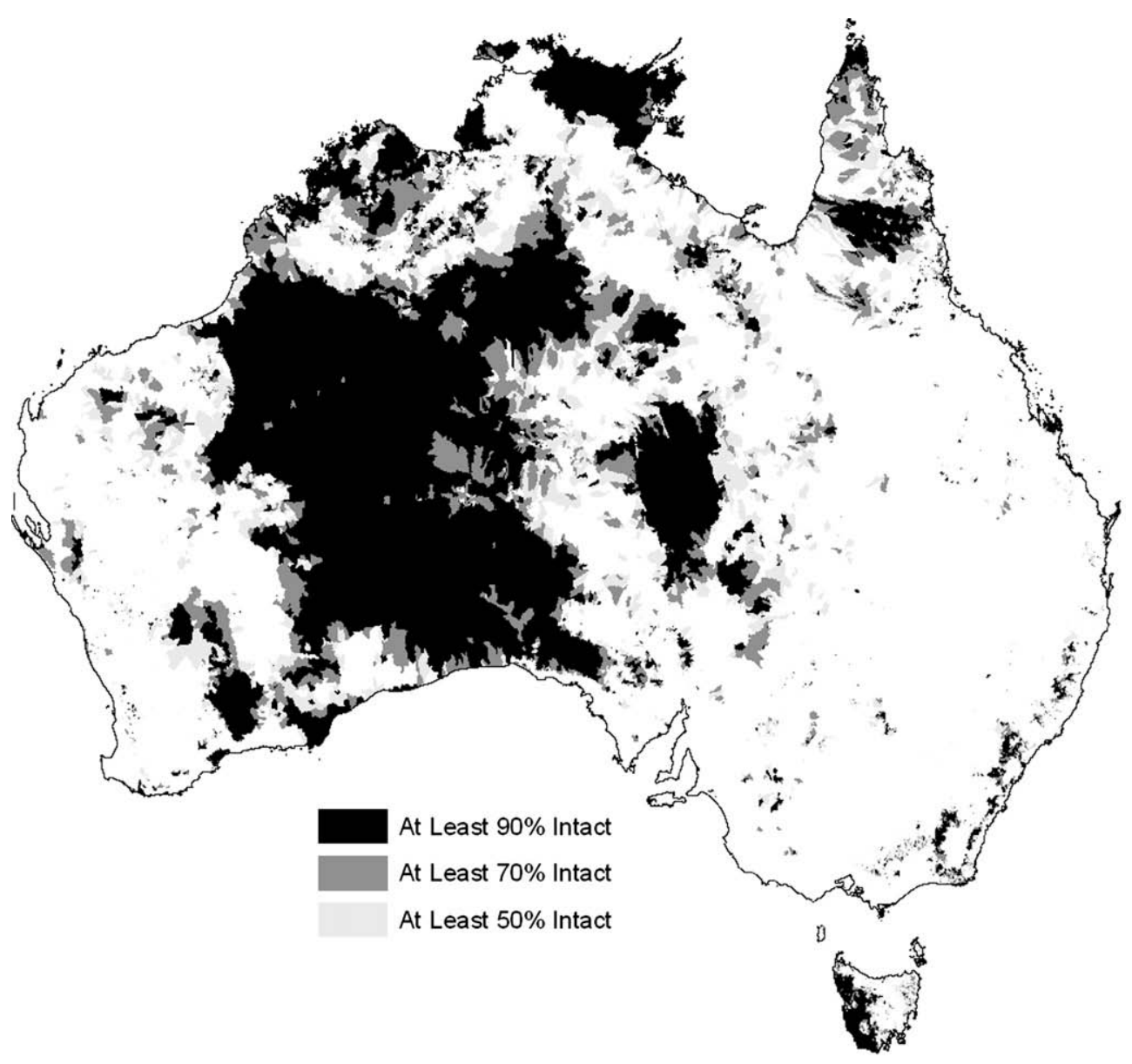

Fig. 2. Sub-catchments containing at least $50 \%, 70 \%$, and $90 \%$ of relatively unmodified native vegetation. 


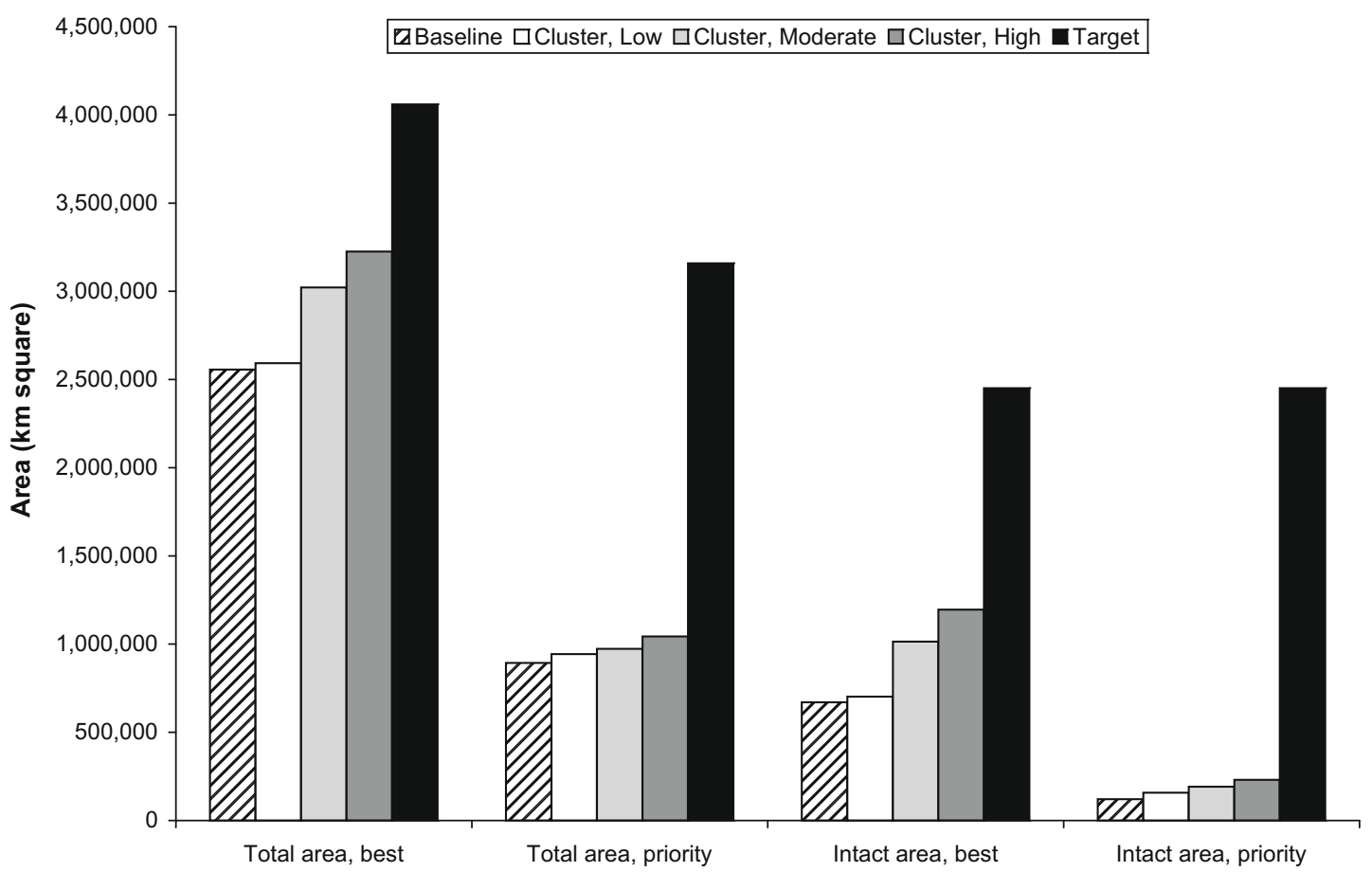

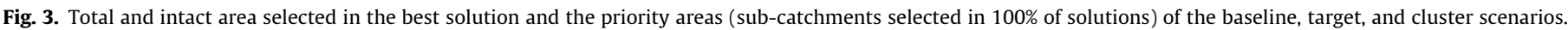
Three different cluster solutions are displayed, each with a different degree of importance placed on identifying groups of intact planning units.

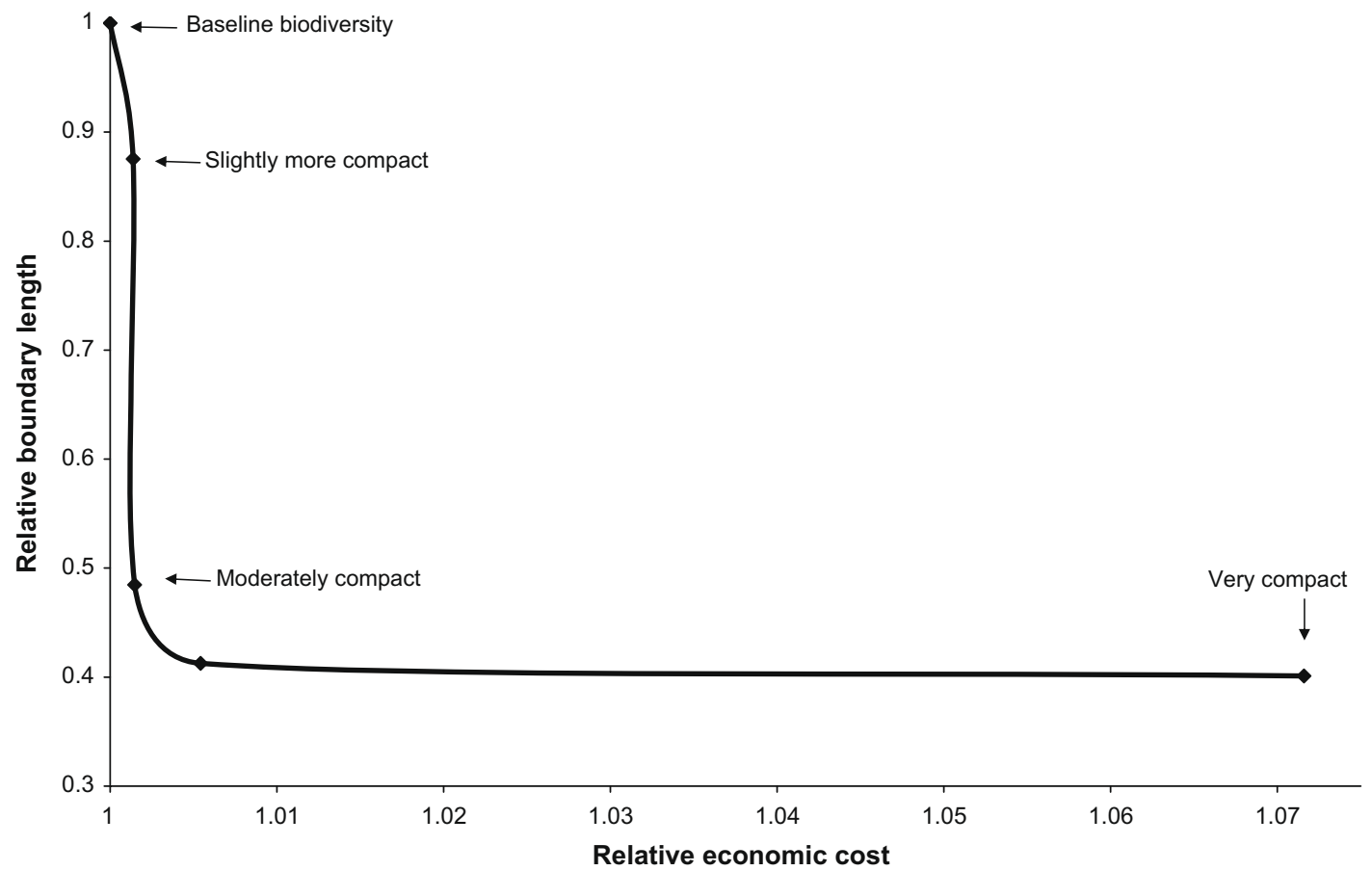

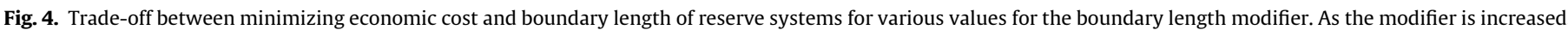

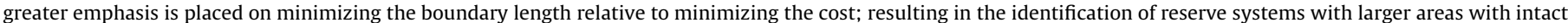
native vegetation (higher wilderness quality). The total boundary length versus cost of scenarios that used low, moderate, and high degree of clustering are shown.

\section{Discussion}

The long-term conservation of biodiversity requires consideration of multiple conservation objectives, and especially (1) the representation of known species and ecosystem types and (2) the protection of areas with high wilderness quality, a surrogate for the long-term persistence of biodiversity. It is important to consider both these conservation objectives when identifying priorities for conservation investment. The places that achieve one objective will not necessarily achieve the other objective, unless explicitly sought (Balmford et al., 2001). We tested two alternative approaches that aimed to cost-effectively identify large intact areas and include at 

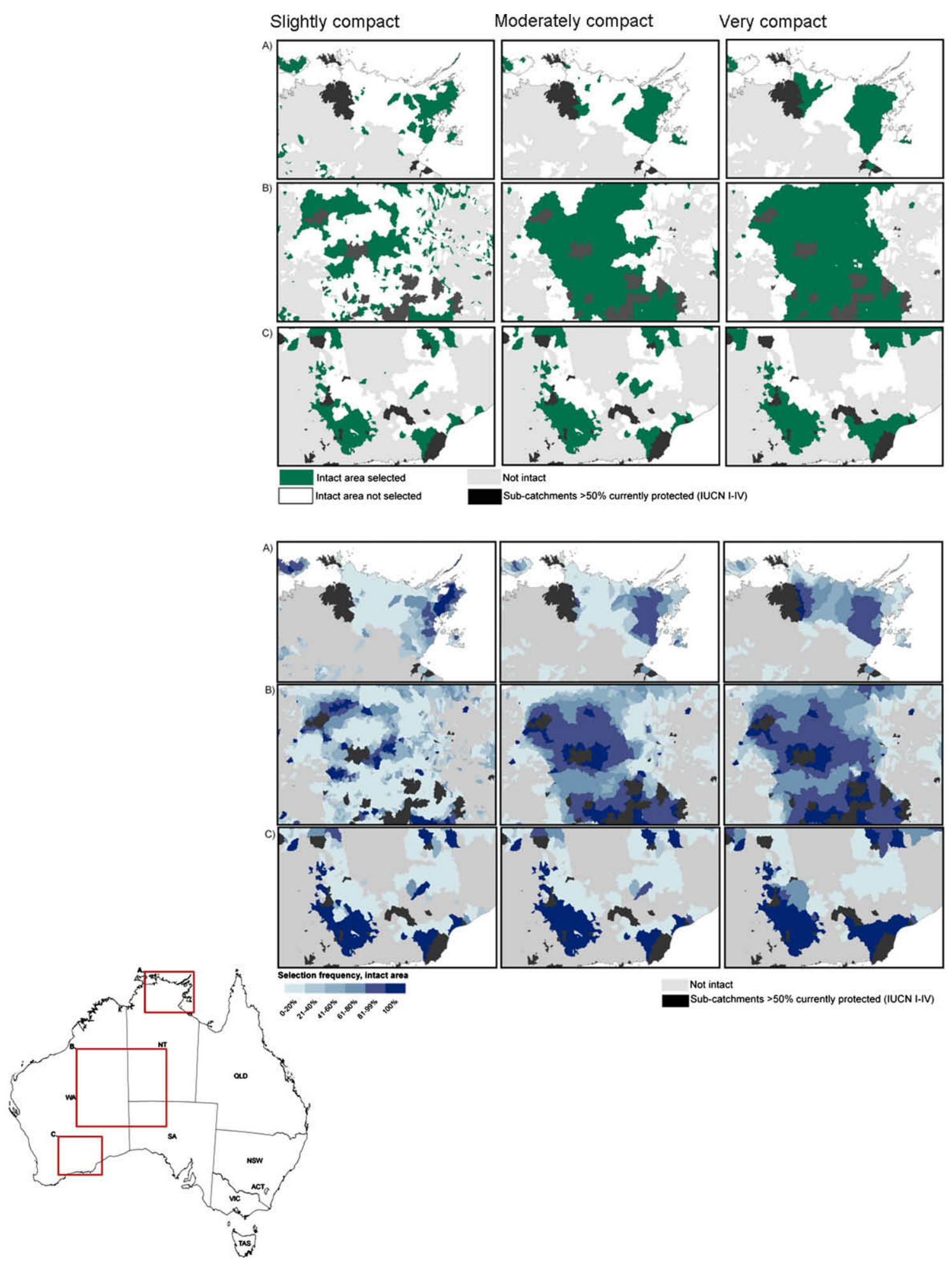

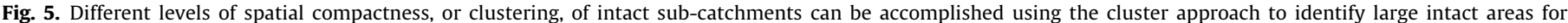

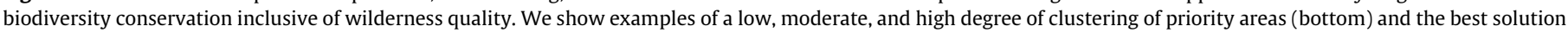

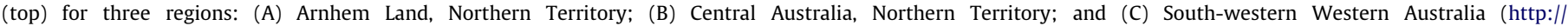
www.gondwanalink.org).

least $30 \%$ of the pre-European range of each biodiversity feature. In both approaches, we assume the conservation action under consideration is land acquisition and aim to meet the planning objectives for the smallest acquisition cost possible. However, our methodology can be readily modified to consider other conservation management options so long as comprehensive data on the cost of these activities are available (Carwardine et al., 2008).

\subsection{Target scenario}

The typical approach to systematic priority setting for biodiversity conservation is to achieve biodiversity goals for a minimum economic cost, as done in the baseline approach. Since this approach will only prioritize intact areas needed to achieve biodiversity targets, we placed additional constraints on this problem such 


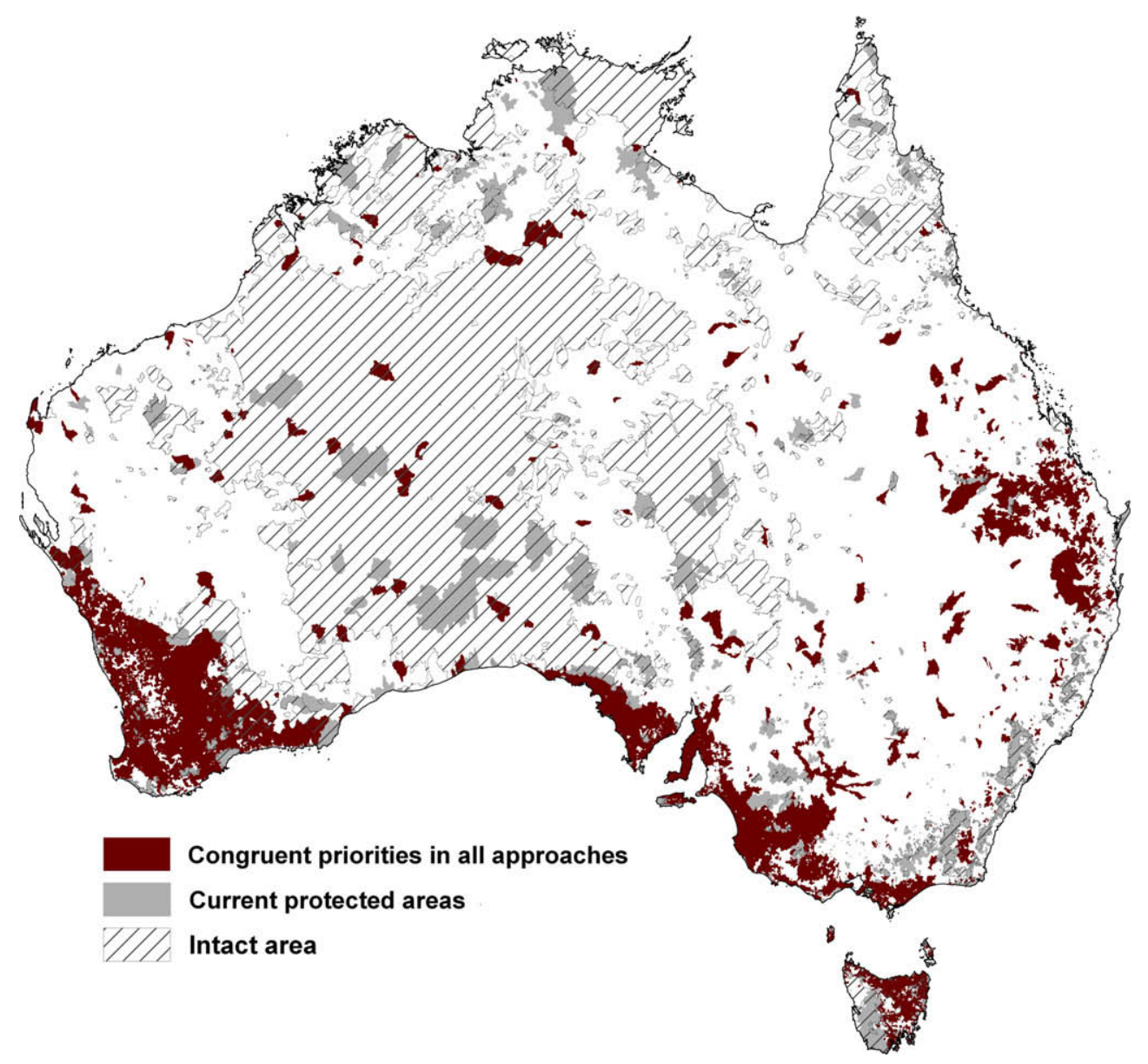

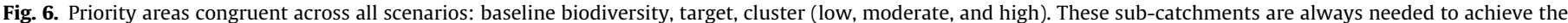
objective of protecting $30 \%$ of the pre-clearing extent of each biodiversity feature.

that biodiversity goals were to be achieved within intact subcatchments, when possible. The result of this constraint was that $100 \%$ of the extent of intact area was identified as irreplaceable. The high priority of the intact sub-catchments is explained by the following: (1) the entire intact extent of $56 \%$ of the species that occur in intact areas were required to achieve the biodiversity goals; and (2) all intact sub-catchments contained a portion of at least one of these biodiversity features. Although our objective of achieving large intact areas was achieved, the outcome would be extremely expensive to implement as it requires a large portion of Australia's area. This approach could produce less expensive options if the biodiversity conservation goal in the intact sub-catchments were reduced but the ecologically meaningful threshold (i.e. conservation target) amount would be challenging to identify. Furthermore, it would not guarantee that the intact area identified was compact. A more direct approach at identifying large intact areas is desirable and provided in the cluster approach.

\subsection{Cluster scenario}

The importance of large intact priority areas can be traded-off against the importance of minimizing the cost of the reserve system. Typically, this would be applied to the entire study region to identify compact priority areas for conservation (Klein et al., 2008; Stewart and Possingham, 2005). We modified this approach to place emphasis on identifying large priorities in intact areas only, allowing for trade-offs to be made between economic costs of conservation and the size of conservation areas identified across intact landscapes. This approach is useful because it identifies the most cost-effective groups of intact sub-catchments that contribute to both biodiversity and wilderness objectives. In addition it demonstrates how expenditure will influence the size and location of intact priority areas. For example, in comparing the baseline biodiversity approach to the high cluster scenario we found that a 7\% increase in expenditure would achieve solutions with a boundary that is $60 \%$ smaller; hence, a small cost increase results in the protection of more compact areas (Fig. 5). However, the trade-off is likely to be different in different study regions because it is dependent upon the economic data used to represent the costs of conservation.

We recognize that the cost data used in this study may not accurately reflect the cost of acquiring land in Australia and that the estimated cost of acquiring more land across the intact landscapes may not be accurate. Although wilderness areas are predicted to be less expensive to acquire relative to more intensively used zones in Australia (Carwardine et al., 2008; Pimm et al., 2001), the large area of land needed to conserve wilderness may not be available for acquisition per se (e.g. unallocated crown land, Indigenous land, and land that is owned privately with an unwilling seller). However, the cost reflects the relative cost of conservation investment in other management actions (Balmford et al., 2003). Off-reserve conservation actions, such as stewardship agreements with land holders, are also necessary in achieving desired conservation outcomes of protecting wilderness and biodiversity (Mackey et al., 1998). Using our framework, priorities for other conservation actions could be identified given spatially 
explicit information about the costs of implementing other conservation actions (e.g. weed and feral animal management) (Carwardine et al., 2008). In addition, many areas identified as priorities for conservation, such as those in Arnhem Land and Central Australia in the Northern Territory, are Aboriginal land that can not be purchased for conservation (Fig. 5). These areas were included in our analysis because conservation mechanisms have been established that allow for National Parks to occur on Aboriginal Land. In fact, between 1997 and 2006, 66\% of the land added to Australia's National Reserve System was contributed through the Indigenous Protected Area Programme (Gilligan, 2006).

Regardless of the approach employed to conserve biodiversity, certain catchments will always be needed to achieve the objective of representing $30 \%$ of each biodiversity feature. For example, in south western Australia, only small portions of the original extent of many species' distributions exist due to the extensive land clearing that has occurred in this region. The small portions of these distributions are necessary to achieve the biodiversity goals regardless of approach. Since these areas are not large or intact, they would not be captured if wilderness conservation was the only objective.

There are various definitions of wilderness in Australia and elsewhere (Mackey et al., 1998). Consistent with more recent usage, we have adopted a definition which reflects the wilderness continuum concept and is primarily based on identifying relatively large and intact areas that have not been subject to broad-scale clearing and fragmentation. Although the high quality wilderness areas are relatively intact, the biodiversity in wilderness areas so defined may still suffer the effects of other more diffuse and indirect threatening processes such as introduced species, changed fire regimes, and grazing (Booth and Traill, 2008; Mackey et al., 1998; Woinarski et al., 2007). Also, wilderness areas can (and indeed generally do) support human communities, as within the definition used here it is the kind of land use activity and its ecological impact that determines wilderness quality not the presence or absence of people. In order to delineate intact areas, we use a dataset that reflects the condition of vegetation in Australia. Other definitions of wilderness could be adopted, and additional datasets used, to apply the approaches presented in this paper.

Investment in both (a) representation of elements of biodiversity (e.g. species, habitats) and (b) wilderness conservation is not only complementary but important for the long-term persistence of biodiversity. Using the principles of systematic conservation planning, we developed two approaches to identify areas important for the conservation of biodiversity in terms of both wilderness quality and biodiversity representation, using Australia as a case study. Although the generality of our results to other planning regions is unknown, our approaches could be applied to other geographic regions at various scales, given availability of spatial data on vegetation condition, biodiversity, and conservation costs. This manuscript provides a novel framework to identify cost-effective biodiversity conservation priorities inclusive of wilderness quality.

\section{Acknowledgements}

The authors would like to thank the following scientists for participating in the project workshops and contributing towards the development of this work: Annemarie Watt Mark Burgman, Bruce Cummings, Craig James, Simon Linke, John Morley, Bob Pressey, David Roshier, Paul Sattler, Richard Thackway, Kristin Williams, and John Woinarski. We would also like to thank the following people and organizations for providing data used in this project: Australian Government Department of Environment and Water Resources, Australian National University, Birds Australia, Geosciences Australia, Richard Thackway, and Robert Lesslie. The environmental domains used in this paper were generated from re- search supported by ARC Linkage Grant LP0455163. This paper was, in part, financially supported by a grant from the Commonwealth Environmental Research Facility.

\section{References}

Australian Government, 2004. Interim Biogeographic Regionalization for Australia Version 6.1. Australian Government Department of the Environment, Water, Heritage and the Arts, Canberra. <http://www.environment.gov.au/parks/nrs/ science/bioregion-framework/ibra/index.html> (Accessed 11.9.2008.).

Ball, I.R., Possingham, H.P. 2000. Marxan (V1.8.2): Marine Reserve Design Using Spatially Explicit Annealing User Manual, Brisbane. <http://www.uq.edu.au/ marxan/> (Accessed 4.8.2008.)

Balmford, A., Gaston, K.J., Blyth, S., James, A., Kapos, V., 2003. Global variation in terrestrial conservation costs, conservation benefits, and unmet conservation needs. Proceedings of the National Academy of Sciences of the United States of America 100, 1046-1050.

Balmford, A., Moore, J.L., Brooks, T., Burgess, N., Hansen, L.A., Williams, P., Rahbek, C., 2001. Conservation conflicts across Africa. Science 291, 2616-2619.

Birds Australia, 2005. Atlas of Australian Birds User Manual. Royal Australian Ornithologists Union, East Hawthorn.

Booth, C., Traill, B. 2008. Conservation of Australia's Outback Wilderness. Wild Australia Program Pew Environment Group, Maleny. <http://www.pewtrusts. org/uploadedFiles/wwwpewtrustsorg/Reports/Wilderness_protection/aaa\% 20outback\%20wilderness\%20study\%20may\%2014th.pdf $>$ (Accessed 8.9.2008.).

Burgman, M.A., Fox, J.C., 2003. Bias in species range estimates from minimum convex polygons: implications for conservation and options for improved planning. Animal Conservation 6, 19-28.

Callicott, J., Nelson, M., 1998. The Great New Wilderness Debate. University of Georgia Press, Atlanta.

Carwardine, J., Wilson, K., Watts, M., Etter, A., Klein, C., Possingham, H., 2008. Avoiding costly conservation mistakes: the importance of defining actions and costs in spatial priority setting. Plos One 3, e2586.

Commonwealth of Australia, 1999. Environment Protection and Biodiversity and Conservation Act. Australian Government Department of the Environment and Water Resources.

Commonwealth of Australia, 2005. Direction for the National Reserve System: A Partnership Approach, Canberra. <http://www.environment.gov.au/parks/ publications/nrs/directions.html $>$. (Accessed 9.7.2008.)

Cowling, R.M., Pressey, R.L., Rouget, M., Lombard, A.T., 2003. A conservation plan for a global biodiversity hotspot - the Cape Floristic Region, South Africa. Biological Conservation 112, 191-216.

Cronon, W., 1995. Uncommon ground: toward reinventing nature. W.W. Norton \& Co., New York.

Department of the Environment, Water Resources, Heritage and the Arts, 2008. National Reserve System. Australian Government, Canberra. <http://www. environment.gov.au/minister/garrett/2008/pubs/mr20080331.pdf >. (Accessed 22.6.2008.).

Fahrig, L., 1997. Relative effects of habitat loss and fragmentation on population extinction. Journal of Wildlife Management 61, 603-610.

Frankel, O.H., Soule, M.E., 1981. Conservation and Evolution. Cambridge University Press, Cambridge.

Geider, R.J., Delucia, E.H., Falkowski, P.G., Finzi, A.C., Grime, J.P., Grace, J., Kana, T.M., La Roche, J., Long, S.P., Osborne, B.A., Platt, T., Prentice, I.C., Raven, J.A., Schlesinger, W.H., Smetacek, V., Stuart, V., Sathyendranath, S., Thomas, R.B., Vogelmann, T.C., Williams, P., Woodward, F.I., 2001. Primary productivity of planet earth: biological determinants and physical constraints in terrestrial and aquatic habitats. Global Change Biology 7, 849-882.

Gilligan, B., 2006. The National Reserve System Programme. Commonwealth of Australia, Canberra. <http://www.environment.gov.au/parks/publications/nrs/ pubs/evaluation-2006.pdf $>$. (Accessed 12.9.2008.).

Gilmore, S., Mackey, B., Berry, S., 2007. The extent of dispersive movement behaviour in Australian vertebrate animals, possible causes, and some implications for conservation. Pacific Conservation Biology 13, 120-127.

Glanznig, A., 1995. Native vegetation clearance habitat loss and biodiversity decline: an overview of recent native vegetation clearance in Australia and its implications for biodiversity. Department of Environment, Sport and Territories, Canberra.

Grumbine, R.E., 1990. Viable Populations, Reserve Size, and Federal Lands Management - a Critique. Conservation Biology 4, 127-134.

Hannah, L., Carr, J.L., Lankerani, A., 1995. Human disturbance and natural habitat: a biome level analysis of a global dataset. Biodiversity and Conservation 4, 128155 .

IUCN, 2003. Recommendations of the Vth IUCN World Parks Congress. IUCN (The World Conservation Union), Gland, Switzerland.

Kenney, J., 2007. Global conservation groups announce major effort to protect Australian's bush, deserts, and oceans. The Pew Charitable Trusts. <http:// www.pewtrusts.org/news_room_detail.aspx?id=26436>. (Accessed 25.8.2007.).

Klein, C., Chan, A., Kircher, L., Cundiff, A., Hrovat, Y., Gardner, N., Scholz, A., Kendall, B., Airame, S., 2008. Striking a balance between biodiversity conservation and socioeconomic viability in the design of marine protected areas. Conservation Biology 22, 691-700.

Klein, C., Wilson, K.A., Watts, M., Stein, J., Berry, S., Carwardine, J., Stafford Smith, D.M., Mackey, B., Possingham, H., 2009. Incorporating ecological and 
evolutionary processes into continental-scale conservation planning. Ecological Applications 19, 206-217.

Lesslie, R., 1991. Wilderness survey and evaluation in Australia. Australian Geographer 22, 35-43.

Mackey, B., Berry, S., Brown, T., 2008. Reconciling approaches to biogeographic regionalization: a systematic and generic framework examined with a case study of the Australian continent. Journal of Biogeography 35, 213-229.

Mackey, B., Lesslie, R., Lindenmayer, D., Nix, H., Incoll, R. 1998. The Role of Wilderness in Nature Conservation. The Australian National University, Canberra. http://www.environment.gov.au/heritage/publications/anlr/ rolewild.html. (Accessed 3.3.2007.).

Margules, C.R., Pressey, R.L., 2000. Systematic Conservation Planning. Nature 405, 243-253.

Mittermeier, R.A., Mittermeier, C.G., Brooks, T.M., Pilgrim, J.D., Konstant, W.R., da Fonseca, G.A.B., Kormos, C., 2003. Wilderness and biodiversity conservation. Proceedings of the National Academy of Sciences of the United States of America 100, 10309-10313.

Mittermeier, R.A., Myers, N., da Fonesca, G.A.B., Olivieri, S., 1998. Biodiversity hotspots and major tropical wilderness areas: approaches to setting conservation priorities. Conservation Biology 12, 516-520.

Mittermeier, R.A., Robles Gil, P., Pilgrim, J., Brooks, T., Mittermeier, C.G., Lamoreux, J., da Fonseca, G.A.B., 2004. Hotspots: Revisited. CEMEX, Mexico.

Mulvaney, J., Kamminga, J., 1999. Prehistory of Australia. Allen \& Unwin, Sydney.

Naidoo, R., Balmford, A., Ferraro, P.J., Polasky, S., Ricketts, T.H., Rouget, M., 2006. Integrating economic costs into conservation planning. Trends in Ecology and Evolution 21, 681-687.

Pimm, S.L., Ayres, M., Balmford, A., Branch, G., Brandon, K., Brooks, T., Bustamante, R., Costanza, R., Cowling, R., Curran, L.M., Dobson, A., Farber, S., da Fonseca, G.A.B., Gascon, C., Kitching, R., McNeely, J., Lovejoy, T., Mittermeier, R.A., Myers, N., Patz, J.A., Raffle, B., Rapport, D., Raven, P., Roberts, C., Rodriguez, J.P., Rylands, A.B., Tucker, C., Safina, C., Samper, C., Stiassny, M.L.J., Supriatna, J., Hall, D.H., Wilcove, D., 2001. Environment - can we defy nature's end? Science 293, 22072208.

Possingham, H.P., Ball, I.R., Andelman, S., 2000. Mathematical methods for identifying representative reserve networks. In: Ferson, S., Burgman, M. (Eds.), Quantitative Methods for Conservation Biology. Springer-Verlag, New York, pp. 291-305.

Possingham, H.P., Wilson, K.A., Andelman, S.J., Vynne, C.H., 2006. Protected areas: goals, limitations, and design. In: Groom, M.J., Meffe, G.K., Carroll, C.R. (Eds.), Principles of Conservation Biology. Sinauer Associates Inc., Sunderland, MA, pp. 509-533.
Pressey, R.L., Cowling, R.M., Rouget, M., 2003. Formulating conservation targets for biodiversity pattern and process in the Cape Floristic Region South Africa. Biological Conservation 112, 99-127.

Redford, K.H., Coppolillo, P., Sanderson, E.W., da Fonseca, G.A.B., Dinerstein, E. Groves, C., Mace, G., Maginnis, S., Mittermeier, R.A., Noss, R., Olson, D., Robinson, J.G., Vedder, A., Wright, M., 2003. Mapping the conservation landscape. Conservation Biology 17, 116-131.

Sarkar, S., 1999. Wilderness preservation and biodiversity conservation - keeping divergent goals distinct. Bioscience 49, 405-412.

Solan, M., Cardinale, B.J., Downing, A.L., Engelhardt, K.A.M., Ruesink, J.L., Srivastava, D.S., 2004. Extinction and ecosystem function in the marine benthos. Science 306, 1177-1180.

Soule, M., Mackey, B., Recher, H., Williams, J., Woinarski, J., Driscoll, D., Dennison, W., Jones, M., 2004. The role of connectivity in Australian conservation. Pacific Conservation Biology 10, 266-279.

Soulé, M.E., Sanjayan, M.A., 1998. Conservation targets: do they help? Science 279, 2060-2061.

Stewart, R.R., Possingham, H.P., 2005. Efficiency, costs and trade-offs in marine reserve system design. Environmental Modeling and Assessment 10, 203-213.

Thackway, R., Lesslie, R., 2006. Reporting vegetation condition using the Vegetation Assets, States, and Transitions (VAST) framework. Ecological Management \& Restoration 7, s53-s62.

Thackway, R., Lee, A., Donohue, R., Keenan, R.J., Wood, M., 2007. Vegetation information for improved natural resource management in Australia. Landscape and Urban Planning 79, 127-136.

The National Vegetation Information System, 2001. Executive Steering Committee for Australian Vegetation Information, Canberra.

Thompson, J.N., 2005. Coevolution: the geographic mosaic of coevolutionary arms races. Current Biology 15, R992-R994.

United Nations, 1992. Convention on Biological Diversity, Rio de Janeiro.

Williams, P., Gibbons, D., Margules, C., Rebelo, A., Humphries, C., Pressey, R., 1996 A comparison of richness hotspots, rarity hotspots, and complementary areas for conserving diversity of British birds. Conservation Biology 10, 155174.

Woinarski, J., Mackey, B., Nix, H., Trail, B. 2007. The Nature of Northern Australia, Canberra.

World Conservation Union, 1994. Guidelines for Protected Area Management Categories. IUCN, Gland and Cambridge. 